20

\title{
Микроскопия с многофотонным возбуждением для идентификации и оперативного контроля компонентов внеклеточного матрикса тканей организма
}

\author{
(C) Ю.В. Кистенев ${ }^{1,2}$, В.В. Николаев ${ }^{1,3}$, А.В. Борисов ${ }^{1,2}$, О.Б. Заева ${ }^{1}$, А.И. Князькова ${ }^{1,3}$, Н.А. Кривова $^{1}$ \\ ${ }^{1}$ Национальный исследовательский Томский государственный университет, \\ 634050 Томск, Россия \\ ${ }^{2}$ Сибирский государственный медицинский университет, \\ 634050 Томск, Россия \\ ${ }^{3}$ Институт физики прочности и материаловедения Сибирского отделения РАН, \\ 634055 Томск, Россия \\ e-mail: yuk@iao.ru
}

Поступила в редакцию 11.12.2019 г.

В окончательной редакции 12.02.2020 г.

Принята к публикации 28.02.2020 г.

Процесс выделения внеклеточного матрикса (ВКМ) требует оперативного контроля, поскольку при неоптимальных параметрах процесса существует опасность разрушения основных белков клеточного матрикса. С использованием многофотонной микроскопии исследована структура коллагена, целостность клеточной мембраны и содержание эластина в процессе выделения ВКМ из различных тканей организма крыс (мозг, дерма, мышца). Показано, что многофотонная микроскопия является эффективным инструментом контроля качества выделения ВКМ.

Ключевые слова: многофотонная микроскопия, внеклеточный матрикс, коллаген.

DOI: $10.21883 /$ OS.2020.06.49412.50-20

\section{Введение}

Исследование внеклеточного матрикса (ВКМ) и его компонентов является одним из наиболее актуальных направлений для клеточной биологии и физиологии, тканевой инженерии в силу его интегрирующей роли для тканей организма [1,2].

В настоящее время для анализа отдельных компонентов ВКМ используется набор биохимических методов, которые потенциально могут давать смещенные оценки, например для протеомного анализа требуется исключение попадания внутриклеточных белков [3-5]. При разработке протоколов выделения ВКМ необходима идентификация его компонентов и оперативный контроль эффективности разделения клеточной и внеклеточной фаз. Протоколы децеллюляризации, как правило, разрабатываются для целей тканевой инженерии, создания скаффолдов и включают в себя физические, ферментативные и химические этапы. К физическим методам относятся механическое воздействие, циклы замораживания-оттаивания, обработка ультразвуком. При ферментативной децеллюляризации используются трипсин, эндо- и экзонуклеазы. Широко применяются и химические детергенты - кислоты и щелочи, ферменты, гипертонические и гипотонические растворы, ионные и неионные детергенты, хелатирующие агенты и бимодальные детергенты. Эти реагенты существенно нарушают структуру белков, которые являются компонентами ВКМ и делают невозможным их анализ из-за множественных артефактов [6].
Метод многофотонной микроскопии (МФМ) позволяет визуализировать in vivo объекты микронного уровня, при этом с возможностью проникать в глубину до нескольких сотен микрометров [7]. Метод МФМ основан на нелинейном взаимодействии оптического излучения с веществом, при котором в одном элементарном акте поглощения участвует несколько фотонов с энергией $h v$. Во время процесса поглощения происходит переход из начального квантового состояния с энергией $E_{1}$ в конечное состояние с энергией $E_{2}$, при котором разница энергий состояний равна сумме энергий поглощенных фотонов.

Использование режима измерения времени жизни флуоресценции (Fluorescence Lifetime Imaging Microscopy, FLIM) дает возможность оценить пространственное распределение нескольких флуорофоров в ткани в условиях наложения сигналов флуоресценции. Режим FLIM позволяет исследовать концентрацию ионов в биоткани, компонентный состав клеток, оценивать метаболическое состояние тканей и клеток [8-12]. Чаще всего для анализа данных времени жизни автофлуоресценции используют двухэкспонециальную модель:

$$
F(x, y, t)=a_{1}(x, y) e^{-\frac{t}{\tau_{1}(x, y)}}+a_{2}(x, y) e^{-\frac{t}{\tau_{2}(x, y)}} .
$$

где $x$ и $y-$ координаты пикселя, $a_{1}, a_{2}$ - амплитуды, $\tau_{1}, \tau_{2}$ - короткое и длинное времена жизни автофлуоресценции [13].

Многофотонная накачка среды короткими (фемтосекундными) импульсами позволяет также генерировать 


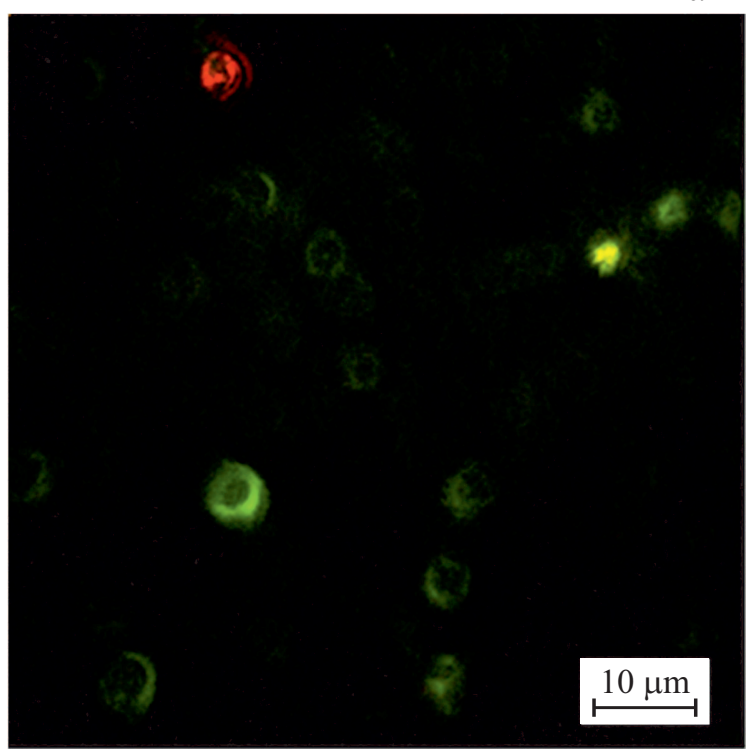

$b$

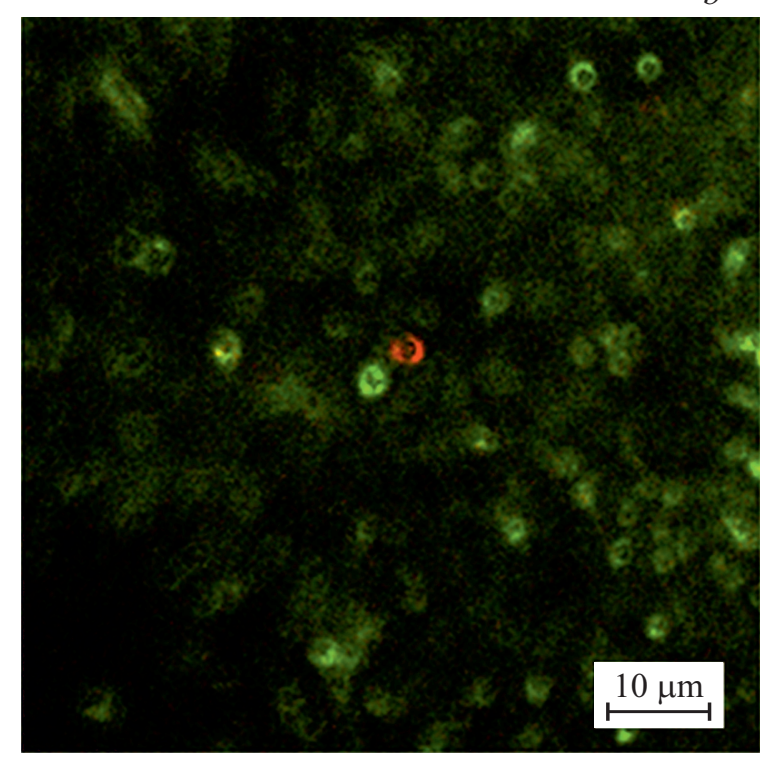

Рис. 1. Ткани мышцы после обработки на магнитной мешалке в течение $1 \mathrm{~h}$ в фильтрате $(a)$, в осадке $(b)$. Сигнал АФ показан зеленым цветом, сигнал ГВГ — красным.

различные гармоники в зависимости от симметрии отдельных молекул. На практике, как правило, используется сигнал генерации второй гармоники (ГВГ) для визуализации коллагена.

Таким образом, МФМ позволяет получать подробную информацию о морфологии живой ткани в режиме реального времени с использованием комбинации автофлуоресценции (АФ) и ГВГ. МФМ позволяет проводить in vitro и ex vivo диагностику необработанных тканей без маркировки или окрашивания $[14,15]$. Показано, что данные методы визуализации позволяют анализировать ВКМ в естественной среде без артефактов [16-18]. Данные достоинства МФМ для визуализации ВКМ были учтены в настоящем исследовании.

Целью работы является исследование возможности оценки качества выделения ВКМ с использованием метода МФМ.

\section{Материалы и методы}

В экспериментах использовали крыс-самцов Вистар, масса тела 200-250 g, полученных из питомника Института фармакологии СО РАМН. Животных содержали в соответствии с правилами, принятыми Европейской конвенцией по защите позвоночных животных, используемых для экспериментальных и иных научных целей (Страсбург, 1986).

После слабого эфирного наркоза и последующей эвтаназии с помощью гильотины у крыс были взяты образцы тканей: лобной доли мозга, мышц и кожи. Образцы тканей были выбраны с учетом различия их структурно-функциональной организации - объема ВКМ, количества функциональных клеток, плотности тканей. Образцы кожи обрабатывались дополнительно: с помощью скальпеля отделяли дерму от эпидермиса и в дальнейшем обрабатывали только дерму как наиболее функционально активную часть кожи.

Образцы (массой примерно $150 \mathrm{mg}$ ) промывали от крови, механически измельчали скальпелем и заливали $5 \mathrm{ml}$ физиологического раствора $(0.9 \% \mathrm{NaCl})$. Образцы ткани мозга разделяли и готовили: 1) гомогенат с помощью УЗ гомогенизатора Sonica по стандартной методике и 2) отмывка ВКМ с помощью магнитной мешалки ПЭ-6110. Образцы дермы и мышц обрабатывали только с помощью магнитной мешалки.

Исследовали влияние длительности обработки на магнитной мешалке на сохранность основных структурных компонентов ВКМ (коллагена и эластина) и полноту удаления клеток и их фрагментов. В то же время крайне важным является определение сохранения целостности клеточных мембран, поскольку внутриклеточное содержимое может контаминировать фазу, содержащую ВКМ. Длительность обработки на магнитной мешалке для образцов мозга составляла 30, 60, $120 \mathrm{~min}$, а для образцов дермы - 3 и $24 \mathrm{~h}$ и мышц - 3, 24 и $48 \mathrm{~h}$. Клеточную и матриксную фазы разделяли фильтрованием на бумажном фильтре (синяя лента). В полученных фазах определяли количество клеток и их фрагментов, присутствие и состояние коллагена и эластина.

Снимки сигнала АФ и ГВГ были получены на МФМ MPTflex производства JenLab (Германия). Микроскоп оснащен шарнирным рычагом с NIR-оптикой, что позволяет проводить сканирование практически на любом живом объекте соответствующих размеров. В состав входит программное обеспечение JenLab для обработки изображений с дополнительным модулем для использования 

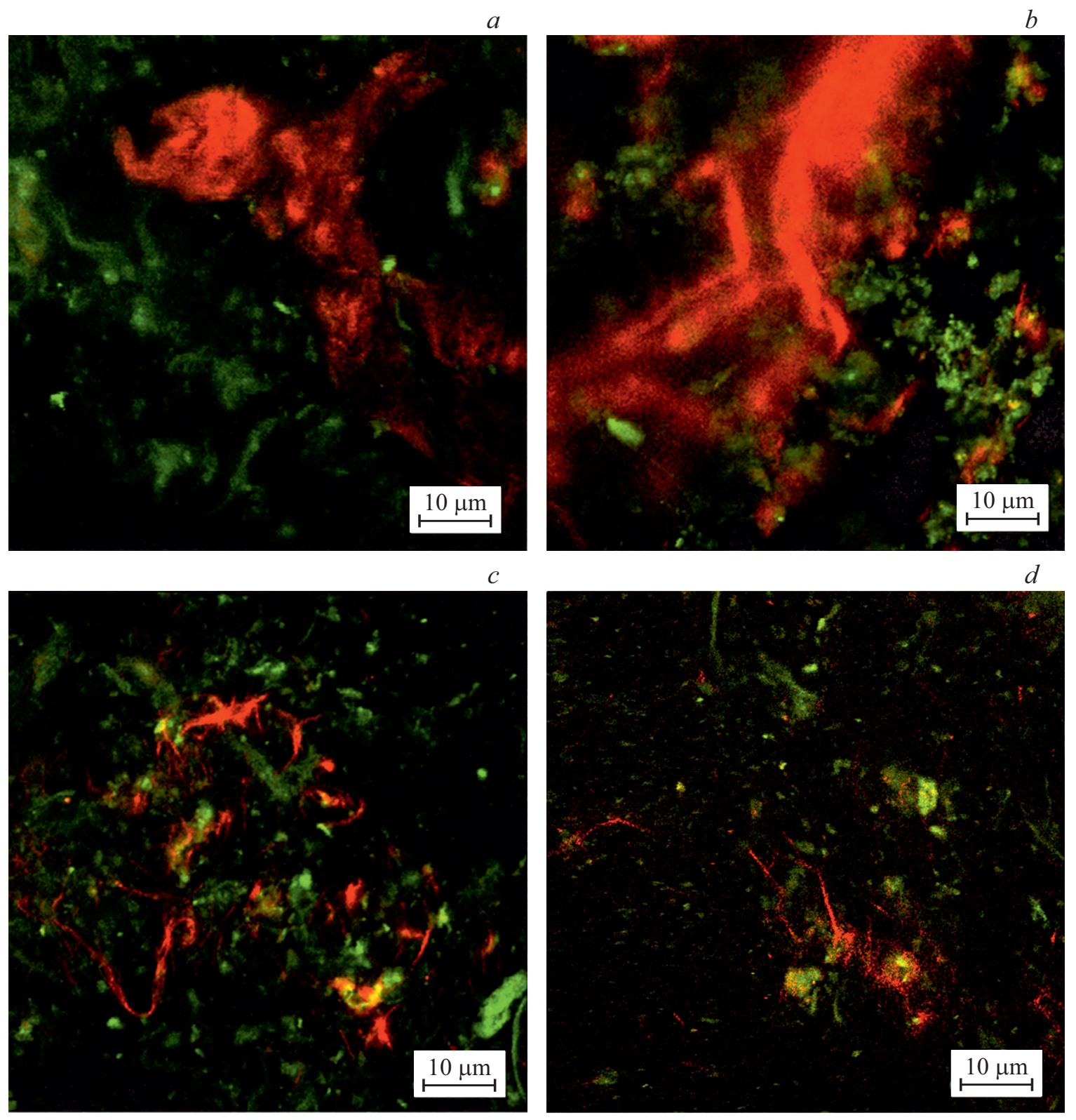

Рис. 2. Примеры МФМ изображений тканей дермы после обработки магнитной мешалкой в течение 3 часов $(a, b)$ и в течение 24 часов $(c, d)$; на изображениях сигнал АФ кодирован зеленым цветом, сигнал ГВГ - красным цветом.

технологии FLIM. Данный МФМ позволяет получать изображения ткани с боковым разрешением около $1 \mu \mathrm{m}$ и продольным разрешением меньше $2 \mu \mathrm{m}$. В устройстве используется два детектора фотонов: первый с фильтром в диапазоне $380 \pm 7 \mathrm{~nm}$ для определения сигнала ГВГ и второй в диапазоне 407-610 nm. Нами использовалась длина волны лазера накачки около $760 \mathrm{~nm}$. При этом структуры коллагена могли наблюдаться при регистрации сигнала ГВГ на длине волны $380 \mathrm{~nm}$. Размер области сканирования был выбран $100 \times 100 \mu \mathrm{m}$, мощность не более $25 \mathrm{~mW}$ с временем сканирования $12 \mathrm{~s}$ на кадр. Данные АФ и ГВГ сохранялись в матрице $512 \times 512$ пикселей приложением JenlabScan. Данные FLIM coxpaнялись в матрицу $128 \times 128$ пикселей приложением SCP
(Becker \& Hickl), накопление сигнала в каждом пикселе составляло не менее 150 фотонов. Также использовалось усреднение в окрестности $3 \times 3$ пиксела для улучшения качества кривой затухания сигнала FLIM.

\section{Результаты}

С использованием методики, описанной в предыдущем разделе, были зарегистрированы и получены по 3 МФМизображения для каждого из 46 образцов.

На основании анализа этих изображений было выявлено, что при обработке тканей мозга в течение $2 \mathrm{~h}$ с использованием магнитной мешалки наблюдается полное 


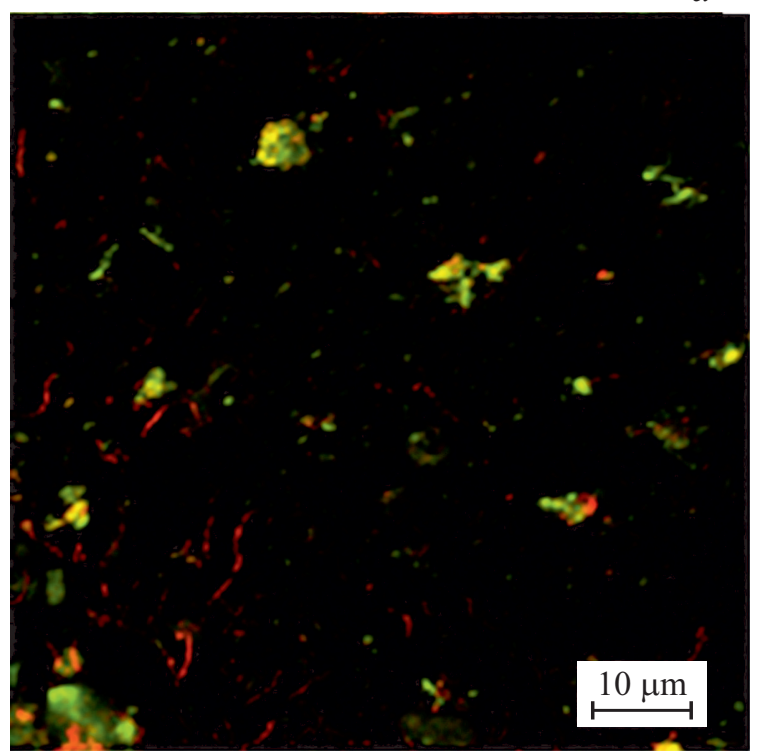

$b$

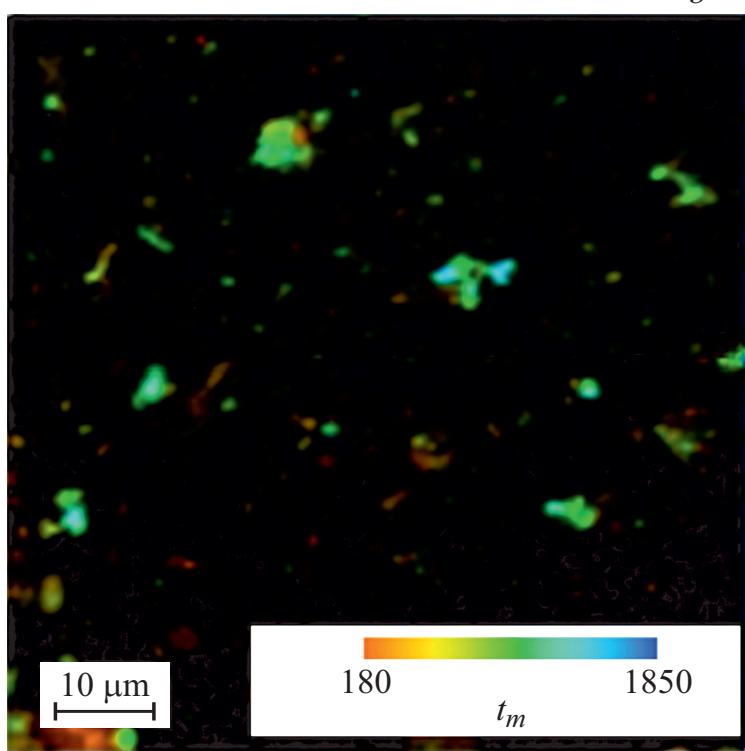

Рис. 3. Фильтрат тканей мозга. $a-$ сигнал АФ показан зеленым цветом, сигнал ГВГ - красным цветом, $b-$ время жизни флуоресценции $t_{m}$.

Параметры тканей, измеренные методом МФМ

\begin{tabular}{|c|c|c|c|c|c|c|}
\hline \multirow{2}{*}{ № } & \multirow{2}{*}{$\begin{array}{c}\text { Проба (время } \\
\text { обработки в часах) }\end{array}$} & \multirow{2}{*}{$t_{1}, \mathrm{ps}$} & \multirow{2}{*}{$t_{2}, \mathrm{ps}$} & \multirow{2}{*}{$t_{m}, \mathrm{ps}$} & \multicolumn{2}{|c|}{ SAAID } \\
\hline & & & & & Q2 & Q3 \\
\hline 1 & Мозг $(0.5 \mathrm{~h})$ & $752 \pm 456$ & $3385 \pm 1015$ & $1496 \pm 350$ & 3.24 & 14.1 \\
\hline 2 & Мозг $(1 \mathrm{~h})$ & $372 \pm 174$ & $2957 \pm 566$ & $1243 \pm 316$ & 3.86 & 17.2 \\
\hline 3 & Мышца (3 h) & $1061 \pm 400$ & $4312 \pm 1096$ & $1765 \pm 250$ & 3.64 & 26.4 \\
\hline 4 & Мышца (24 h) & $986 \pm 214$ & $3225 \pm 629$ & $1312 \pm 161$ & 4.96 & 11.64 \\
\hline 5 & Дерма (3 h) & $1015 \pm 380$ & $3629 \pm 1260$ & $1526 \pm 174$ & 1.01 & 35.4 \\
\hline 6 & Дерма (24 h) & $923 \pm 264$ & $3768 \pm 1419$ & $1494 \pm 282$ & 1.21 & 24.3 \\
\hline
\end{tabular}

растворение образца, обработка в течение $0.5-1 \mathrm{~h}$ сохраняет отдельные клетки и их фрагменты. При обработке тканей мышц на магнитной мешалке клетки сохраняют четкую структуру как в осадке, так в фильтрате и при обработке в течение $3 \mathrm{~h}$ не теряют своей формы. Это хорошо видно при визуализации распределения эластина (сигнал АФ) и коллагена (сигнал ГВГ) (рис. 1).

Образцы ткани мышцы после $24 \mathrm{~h}$ обработки на магнитной мешалке сохраняли отдельные клетки, наблюдалось наличие клеточных конгломератов, коллагена и эластина. При обработке ткани мышцы на магнитной мешалке в течение $48 \mathrm{~h}$ наблюдалось полное разрушение клеток и деградированное состояние коллагена.

Образцы дермы после обработки на магнитной мешалке демонстрировали сохранность отдельных клеток как при 3 h обработке, так и при обработке в течение $24 \mathrm{~h}$ (рис. 2).

После короткой обработки ткани дермы $(3 \mathrm{~h})$ коллаген имел нативную структуру (рис. 2,a, $b$ ), а после длительной обработки $(24 \mathrm{~h})$ коллаген разделяется на более мелкие волокна (рис. 2,c,d).
В таблице приведены параметры времени жизни АФ: среднее время жизни $t_{m}=\left(a_{1} t_{1}+a_{2} t_{2}\right) /\left(t_{1}+t_{2}\right)$, где $t_{1}$, $t_{2}$ - подгоночные параметры в соответствии с (1), индекс „старения кожи“, показывающий отношение сигнала ГВГ к сигналу АФ - в литературе обозначают SAAID (SHG-to-AF aging index of dermis). Индекс вы-

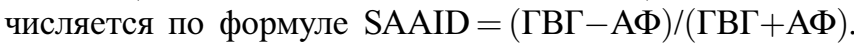
В таблице значения данного индекса представлены в виде границ второго-третьего квартилей распределения измеренных значений.

Видно, что происходит увеличение среднего значения отношения SAAID для тканей после длительной обработки. Мы связываем данные изменения с понижением уровня белка, что снижает АФ и тем самым увеличивает значение SAAID. Что касается времени жизни АФ, мы наблюдали заметное снижение короткого времени $t_{1}$ после длительной обработки ткани с помощью магнитной мешалки. Длинное время $t_{2}$ также уменьшается, однако это уменьшение не столь существенно. Пример изображения тканей мозга в фильтрате после $2 \mathrm{~h}$ обработки на магнитной мешалке представлены на рис. 3. Часто 
изменение времени жизни АФ связывают с изменением метаболического статуса [19], таким образом, представленные результаты свидетельствуют и об изменении данного статуса при выделении ВКМ.

\section{Заключение}

В данной работе были продемонстрированы возможности методов МФМ для анализа ВКМ на примеpe тканей мозга, мышцы и дермы с использованием кратковременной обработки на магнитной мешалке и фильтрования через бумажный фильтр. Полученные результаты позволяют сделать вывод о том, что методы МФМ позволяют провести контроль качества выделения ВКМ. Показано, что данные МФМ позволяют оценить качество сохранности клеточной мембраны в клеточной фазе, а также сохранности структуры коллагена в клеточной и матриксной фазах. Также показано, что при длительной обработке образцов ткани на магнитной мешалке происходят изменения сигналов ГВГ и АФ, а также изменение времени жизни АФ, что свидетельствует об изменении метаболического статуса тканей в процессе выделения ВКМ.

\section{Финансирование работы}

Работа выполнена в рамках Программы фундаментальных научных исследований государственных академий наук на 2013-2020 годы, направление III.23, и научного проекта 8.1.11.2019, выполненного при поддержке программы повышения конкурентоспособности ТГУ.

\section{Соблюдение этических стандартов}

Bсе применимые международные, национальные и институциональные принципы ухода и использования животных были соблюдены.

\section{Конфликт интересов}

Авторы заявляют, что у них нет конфликта интересов.

\section{Список литературы}

[1] Серов В.В., Шехтер А.Б. Соединительная ткань. Функциональная морфология и общая патология. М.: Медицина, $1981.312 \mathrm{c}$.

[2] Pischinger A., Heine H. The Extracellular Matrix and Ground Regulation: Basis for a Holistic Biological Medicine. North Atlantic Books, 2007. 232 p.

[3] de Castro Brás L.E., Ramirez T.A., DeLeon-Pennell K.Y., Chiao Y.A., Ma Y., Dai Q., Halade G.V., Hakala K., Weintraub S.T., Lindsey M.L. // J. Proteomics. 2013. V. 28. N 86. P. 43. doi 10.1016/j.jprot.2013.05.004

[4] Barallobre-Barreiro J., Didangelos A., Yin X., Doménech N., Mayr M. // Methods Mol Biol. 2013. V. 1005. P. 215. doi 10.1007/978-1-62703-386-2_17
[5] Немеи, Е.А., Кирсанова Л.А., Басок Ю.Б., Шагидулин М.Ю., Волкова Е.А., Метельский С.Т., Севастьянов В.И. // Вестник трансплантологии и искусственных органов. 2017. Т. 19. № 4. С. 70.

[6] Kular J.K., Basu S., Sharma R.I. // J. Tissue Engineering. 2014. V. 5. P. 1. doi $10.1177 / 2041731414557112$

[7] Kobat D., Durst M.E., Nishimura N., Wong A.W., Schaffer C.B., Xu C. // Optics Express. 2009. V. 17. N 16. P. 13354. doi 10.1364/OE.17.013354

[8] $X u$ C., Webb W.W. // Topics in Fuorescence Spectroscopy. 1997. V. 5. P. 471.

[9] Huang S., Heikal A.A., Webb W.W. // Biophysical J. 2002. V. 82. N 5. P. 2811. doi 10.1016/S0006-3495(02)75621-X

[10] Conklin M.W., Provenzano P.P., Eliceiri K.W., Sullivan R., Keely P.J. // Cell. Biochem. Biophys. 2009. V. 53. N 3. P. 145. doi 10.1007/s12013-009-9046-7

[11] Berezin M.Y., Achilefu S. // Chem. Rev. 2010. V. 110. N 5. P. 2641.

[12] Becker W. // J. Microsc. 2012. V. 247. N 2. P. 119. doi 10.1111/j.1365-2818.2012.03618.x

[13] Vergen J., Hecht C., Zholudeva L.V., Marquardt M.M., Hallworth R., Nichols M.G. // Microsc. Microanal. 2012. V. 18. N 4. P. 761. doi 10.1017/S1431927612000529

[14] Mazumder N., Balla N.K., Zhuo G.Y., Kistenev Yu.V., Kumar R., Kao F.J., Brasselet S., Nikolaev V.V., Krivova N.A. // Front. Phys. 2019. V. 7. P. 170. doi 10.3389/fphy.2019.00170

[15] Shirshin E.A., Yakimov B.P., Darvin M.E., Omelyanenko N.P., Rodionov S.A., Gurfinkel Y.I., Lademann J., Fadeev V.V., Priezzhev A.V. // Biochemistry (Moscow). 2019. V. 84. N 1. P. 69.

[16] Schenke-Layland K. // J. Biophotonics. 2008. V. 1. N 6. P. 451.

[17] Hinderer S., Layland S.L., Schenke-Layland K. // Advanced Drug. Delivery Rev. 2016. V. 97. P. 260.

[18] Kistenev Y.V., Vrazhnov D.A., Nikolaev V.V., Sandykova E.A., Krivova N.A. // Biochemistry (Moscow). 2019. V. 84. P. 108.

[19] Chakraborty S., Nian F.S., Tsai J.W., Karmenyan A., Chiou A. // Sci. Rep. 2016. V. 13. N 6. P. 19145. doi 10.1038/srep19145 